\title{
Out of the Shadows and into the Spotlight: The Sweeping Evolution of Employment Standards Enforcement in Australia
}

For many years, the federal labour inspectorate in Australia was under-loved and overlooked. However, in 2006, this all changed. The inspectorate - now a statutory agency known as the Office of the Fair Work Ombudsman (FWO) - was unexpectedly thrust into the public spotlight in the wake of controversial legislative reforms introduced by the Howard conservative government (Hardy 2009). Notwithstanding several changes of government since this time, the federal labour inspectorate has continued to play a prominent role in workplace relations. And yet, much like the situation in Ontario, there remains a persistent "enforcement gap" (Berg and Farbenblum 2017; Bright, Fitzpatrick, and Fitzgerald 2017). Indeed, the long-held assumption that the vast majority of Australian employers were law abiding and that non-compliance may be explained "as a moral evil rather than as a consequence of structural factors" (Bennett 1994, 151) has now come unstuck. In 2015 a series of underpayment scandals rocked some of the country's best-known brands, including 7-Eleven and Domino's Pizza (Australian Broadcasting Corporation 2015, 31 August; Australian Broadcasting Corporation 2015, 4 May; Senate Education and Employment References Committee 2017). Four years on, the media continues to be awash with stories of worker exploitation, community concern about wage theft is still high, and the FWO remains under intense scrutiny (Berg and Farbenblum 2018; Clibborn and Wright 2018; Fels and Cousins 2019).

This chapter considers some of the compliance and enforcement challenges presented by employment standards regulation in Australia and the way in which the FWO has sought to respond to the problem of employer non-compliance with workplace laws. We begin by surveying the broader historical, legal, and political processes through which domestic employment regulation and enforcement has emerged and 
continues to evolve in Australia. As part of this overview, we touch on a number of key developments, including the recent passage of statutory reforms designed to better protect vulnerable workers (Fair Work Amendment (Protecting Vulnerable Workers) Act 2017 (Cth)). We then turn to the internal administration of the agency, including the FWO's attempts to move away from an individualized, complaints-oriented approach towards a more "responsive" and "strategic" enforcement model.

\section{An Overview of the Regulatory and Enforcement Framework in Australia}

Historically, the federal conciliation and arbitration system in Australia allowed an independent industrial umpire to resolve collective disputes by imposing protective employment standards across industry sectors or occupational classes in the form of "awards." Trade unions were effectively charged with "policing" this system and were afforded extensive privileges and protections to perform this supervisory function, including rights of entry and legal standing to commence court proceedings (Hardy and Howe 2009; Bennett 1994). During this early period, government labour inspectorates remained in the shadows (Maconachie and Goodwin 2006, 339).

The general neglect of the federal labour inspectorate, which persisted over the course of the twentieth century, appears to have been premised on an assumption that enforcement of employment standards was "unproblematic" (Bennett 1994, 145) and more properly the role of trade unions than government (Hardy and Howe 2009). These perceptions appear to have led to a chronic lack of resources of the federal labour inspectorate (as well as the subnational state enforcement agencies). Severe resource constraints, low penalties, and judicial reluctance to impose heavy fines against employers led labour inspectors to adopt a weak, persuasive compliance approach to enforcement.

This regulatory landscape, and the entrenched role of trade unions within it, began to shift with the introduction of the Workplace Relations Act 1996 (Cth) under the Howard coalition government. This first tranche of statutory reforms encouraged individualization strategies, restricted union rights, and curtailed the powers of the federal industrial tribunal. However, these issues dramatically escalated in 2006 with the controversial introduction of the coalition government's Work Choices legislation (Workplace Relations Amendment (Work Choices) Act 2005 (Cth)). This subsequent set of radical reforms greatly expanded the federal jurisdiction over workplace relations (at the expense of state 
[provincial] jurisdictions) and further curtailed the role of the industrial relations tribunal. It also sought to usurp the collective, award-based framework by entrenching a core set of minimum employment standards in legislation and promoting individual statutory agreements as the industrial instrument of choice.

Replacing a collectivist system with a rights-based model elevated the role of formal enforcement mechanisms utilized by the federal labour inspectorate and overseen by the courts. This new model came at the expense of informal dispute resolution initiated by unions and administered by the federal tribunal.

In the wake of Work Choices, there was growing unease amongst the general public that many hard-won employment conditions had been, or would be, jeopardized by these reforms. In a bid to address these concerns and confirm that entitlements would be duly "protected by law," the Howard coalition government expressed a somewhat surprising enthusiasm for enforcement. While the Work Choices legislation was ostensibly designed to "deregulate" the labour market, the Conservative government provided the federal labour inspectorate with a substantial injection of much-needed funds. ${ }^{1}$ Combined, these factors directly led to a boost in the inspectorate's workforce, a shift in enforcement strategy, and a spike in litigation (Hardy, Howe, and Cooney 2013).

The Rudd Labor government, elected in late 2007, sought to unwind some of the most extreme measures adopted by the previous government. The Fair Work Act 2009 (Cth) (FWA), which mostly came into force on 1 January 2010, removed easy access to individual statutory agreements, reinstated the central place of enterprise bargaining, and restored some sense of regulatory legitimacy to unions. However, the Work Choices legacy lived on in a number of critical respects. For a start, the federal takeover of workplace relations was further consolidated under the FWA, and most businesses and employees in Australia now fall within the federal jurisdiction (rather than under state jurisdiction). Basic working conditions, including minimum rates of pay, leave entitlements, termination, and redundancy pay continue to be embedded in legislation.

The FWA also established the Office of the FWO - the federal agency that has been charged with primary oversight of employment standards regulation in Australia. While the enforcement framework was strengthened and a number of new powers were introduced, funding to the FWO was substantially reduced beginning around 2010 in the wake of the global financial crisis (Workplace Express 2013, 14 May). Resourcing constraints, combined with a perception that the FWO was being too 
aggressive at a time of significant legislative change, prompted a change to the FWO's dominant compliance and enforcement approach (Wilson 2012,30 April). The agency - which had consciously built a reputation as a rigorous enforcer of the laws since 2006 - started to soften its stance in some respects. For example, it downplayed its use of coercive sanctions, emphasized its educational tools, and expanded its dispute resolution activities. The move towards more cooperative approaches was further entrenched following the election of a Conservative coalition government in 2013. While this shift in regulatory narrative and enforcement strategy - which was promoted as a form of "strategic compliance" may have been more economically sustainable and politically palatable, it has proved to be problematic for the agency. One obvious drawback is that much of the day-to-day work of the FWO became less visible (Andrew 2017).

This move towards cooperative approaches may have backfired on the FWO following the explosion of media and public interest in wage theft akin to that in Ontario, documented in chapter 4. In particular, the public portrayal of the FWO as "business friendly" may have exposed the agency to heavy criticism for its part in failing to stem serious wage theft in key segments of the labour market and amongst precarious groups, including temporary migrant workers. In response, the FWO argued that their efforts had been hampered by limitations within the legal framework (FWO 2017d). Numerous public inquiries that explored these issues in the immediate aftermath tended to agree with the FWO's assessment in this respect. Accordingly, a series of far-reaching recommendations were put forward; many have since been acted upon (Senate Education and Employment References Committee 2016; Forsyth 2016; Labour Hire Licensing Act 2017 (Qld) (commenced on 16 April 2018); Labour Hire Licensing Act 2018 (Vic) (commencing 1 November 2019)). ${ }^{2}$

The latest instalment in this potted history is potentially the most momentous - the introduction of Fair Work Amendment (Protecting Vulnerable Workers) Act 2017 (Cth) (PVWA). As the title of the legislation suggests, the PVWA is designed to curb "deliberate and systematic exploitation of workers" in Australia (Minister for Employment 2016-17, ii). In the lead-up to the 2016 election, stamping out wage theft emerged as a key battleground with both parties seeking to outdo the other in this space (Liberal Party of Australia 2016; Australian Labor Party 2016). The coalition government not only promised to plug some of the most glaring statutory holes, it also committed AU\$20 million in additional funding for the FWO. But ultimately, political rhetoric did not match reality. Recent budget assessments indicate that the funding 
received by the FWO has remained virtually frozen over the past three years (Clibborn and Wright 2018, 217).

This move is somewhat unsurprising, given that the introduction of this new set of reforms is sharply at "odds with the Coalition's employer-oriented approach to industrial relations, exemplified by its recent 'crack down' on unions" (Rawling and Schofield-Georgeson 2018; see also Forsyth 2017). While the PVWA is far from perfect, it has still made some regulatory headway. In particular, the amending legislation raised the maximum penalties available for "serious contraventions" to over half a million Australian dollars, extended liability beyond the direct employer to franchisors and holding companies in certain circumstances, reversed the onus of proof where there has been a failure to keep or maintain employment records, and bolstered the investigative powers of the FWO.

With a federal election looming in early 2019, calls for more far-reaching reforms became increasingly urgent. For example, as part of its "Change the Rules" campaign, the Australian Council of Trade Unions argued that the Fair Work Commission (the federal industrial tribunal) should be allowed to conciliate and arbitrate disputes regarding the non-payment of wages (McManus 2018, April), and liability for wage theft should be extended to lead firms in a range of different business formats, such as supply chains and labour hire (Workplace Express 2018, 13 March; Senate Education and Employment References Committee 2018). At the state level, there have been moves to introduce criminal sanctions for deliberate wage theft (Kennedy and Howe 2018; Education, Employment, and Small Business Committee 2018). In short, the regulatory framework and the institutional apparatus remain in a state of great flux in Australia.

\section{The Remit, Responsibilities, and Resources of the Fair Work Ombudsman}

The FWO is responsible for a number of functions under the FWA, including educating employers and employees about workplace rights and taking action to determine and sanction non-compliance with relevant rights and obligations arising under the FWA, its auspices, and other relevant instruments. While the agency is most well known for its work promoting and ensuring compliance with minimum employment standards, the remit of the FWO is fairly broad.

The FWO is responsible for overseeing civil remedy provisions for "adverse action" (which is similar to anti-retaliation provisions), anti-discrimination (a jurisdiction it shares with other state and federal bodies), and sham contracting (otherwise known as employee 
misclassification). Somewhat controversially, the federal agency has also been tasked with supervising union behaviour and has standing to investigate and enforce provisions for unlawful industrial action, coercion, and freedom of association (Hardy 2018).

While it has a very wide mandate, the FWO has very few inspectors. There are approximately 12 million employees and 2 million businesses in Australia (Australian Bureau of Statistics 2017). While not all of these employees fall within the federal system, the vast majority do. And yet, overseeing workplace relations compliance are around 200 Fair Work inspectors. Similar to the Ontario's Ministry of Labour (MOL), the resources allocated to the FWO are "not keeping pace with the growing number of workplaces and workers covered by employment standards" (Vosko, Grundy, and Thomas 2016, 4; see also chapters 2 and 3). This, along with a growing awareness of the limitations of conventional compliance and enforcement, has led the regulator to move away from detailed complaints investigations towards more strategic, experimental, and collaborative initiatives (see Figure 9.1). As the preceding chapters have identified, and as we will explain in greater detail below, these strategies have had mixed success.

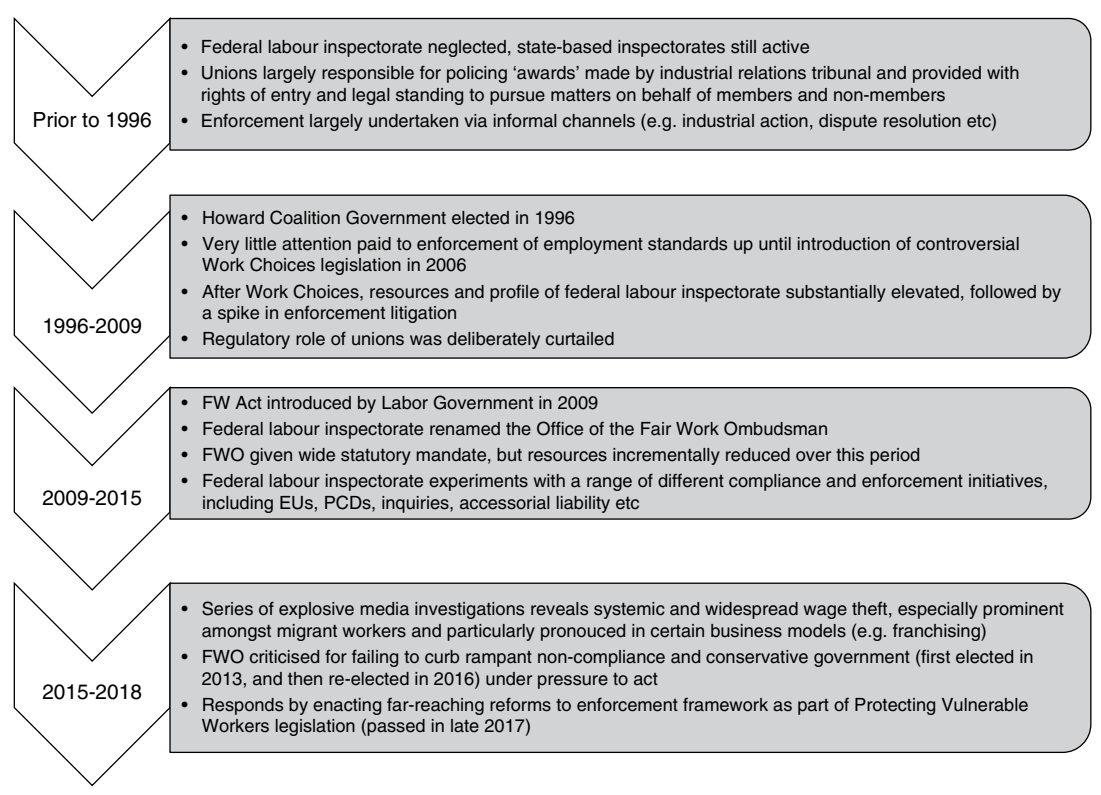

Figure 9.1. Enforcement of Employment Standards in Australia: A Historical Timeline 


\section{Recent Shifts in the FWO's Enforcement Strategy}

In contrast to the adversarial premise of the conciliation and arbitration system, the FWA expressly provides that a key function of the FWO is "to promote harmonious, productive and cooperative workplace relations" (FWA, s. 682). The FWO seeks to fulfil this statutory objective by monitoring, enquiring into, investigating, and enforcing compliance with relevant workplace laws.

Officially, decisions concerning how the FWO approaches its regulatory task, prioritizes resources, and performs key functions are now guided by the Compliance and Enforcement Policy. This policy sets out "guiding principles" that shape the work of the FWO. In particular, the agency seeks to adopt an approach that is "risk-based and proportionate," "open and transparent," and "collaborative," and effects "cultural change" (FWO 2017b, 2-3).

While these principles do not expressly refer to either the theory of responsive regulation or the model of strategic enforcement, they implicitly reflect key tenets of both approaches. For example, the policy states that the FWO will "focus our compliance and enforcement efforts where there is serious non-compliance and where we can deliver the greatest benefit," which is very much in line with the principle of "prioritization" (Weil 2010). In relation to these priority industries, strategic enforcement further suggests that labour inspectorates consider simultaneously whether or not regulatory intervention is likely to be successful in changing compliance behaviour in a way that is both sustainable (limited recidivism) and systemic (has effects beyond the individual firm) (75). It is arguable that both the "sustainability" and "systemic effects" principles have shaped the FWO's thinking in this respect, in that an express aim of the agency, as set out in the Compliance and Enforcement Policy, is to "develop solutions to address structural and behavioural drivers that lead to widespread non-compliance in certain industries and sectors" (FWO 2017b, 3).

Less apparent from the FWO's policy, and arguably from the agency's public documentation more generally, is the principle of deterrence, which is absent to a similar degree in the Ontario case (see chapter 6). Indeed, the FWO's applicable key performance indicators suggest the opposite. In particular, the requirement for the FWO to privilege self-help and dispute resolution strategies over investigation and deterrence-based approaches may be driven by the stated aim to finalize "at least $90 \%$ of requests for assistance involving a workplace dispute ... through education and dispute resolution services" and "no more than 10\% through compliance and enforcement tools" (FWO 2018a, 9; on the parallel situation in Ontario, see chapter 3). The FWO's 
apparent reticence to routinely invoke the principle of deterrence, or use coercive-based sanctions, may be driven by a desire to meet or exceed these key performance indicators.

An alternative reason for downplaying deterrence - and one flagged in earlier chapters - is the enduring legacy, and ongoing influence, of responsive regulation theory and the pyramidal model of enforcement. In line with this theory, a common mantra of the FWO is that "most employers want to do the right thing" (James 2017, 1 May, 1). However, as we discuss below, the notion of what this phrase means has rapidly evolved in response to continuing furore over migrant worker exploitation and political demands for the labour inspectorate to do more to hold lead firms to account.

We turn now to consider how these broad models and guiding principles have shaped the day-to-day operations of the FWO, including the way it detects contraventions, filters complaints, engages in dispute resolution, sanctions employers, and otherwise seeks to leverage key individuals and lead firms to positively contribute towards a culture of compliance.

\section{Education and Assistance}

As noted above, the FWO continues to assume that the majority of employers are put on the path to non-compliance through a lack of information or understanding. Accordingly, the FWO devotes much time and resources to building and disseminating educational materials and self-service tools through various mediums, forums, and campaigns.

Further, since the 2015 underpayment scandal that engulfed 7-Eleven and precipitated a national enforcement crisis, the nature of the FWO's educational offering has rapidly evolved. Rather than simply informing employers of the relevant standards that apply, the FWO has shifted its attention to lead firms. In the last year or so, the FWO released guidance material on labour supply chains that was designed to help businesses monitor and manage their contract arrangements to ensure that all employees throughout the relevant business networks are lawfully engaged and paid (FWO 2018c). Similar guidance materials have been tailored to, and directed at, the franchise sector. In promoting these materials, the FWO has been keen to stress the need for firms to take a range of additional steps to protect their business against brand damage and reputational risks, as well as reduce potential liability (FWO 2018d). In light of the new extended liability provisions introduced under the $P V W A$, the direction to take such steps is less likely to be treated as an empty threat, especially in the franchise sector. 


\section{Detection - Complaints, Campaigns, Tip-offs, and Inquiries}

For some time the FWO has publicly avowed to move away from reactive, complaint-based investigations towards more proactive regulatory techniques (Campbell 2013, May). Nevertheless, it is clear that employee complaints or "requests for assistance involving a workplace dispute" continue to direct much of its compliance and enforcement activity, including dispute resolution work. In 2017/18 the FWO received over 28,000 such requests (FWO 2018a).

While complaints remain central to the FWO's day-to-day operation, the agency is acutely aware that there is "chronic underreporting of exploitation" to the regulator (Senate Education and Employment References Committee 2016, 67), particularly amongst international students. As the former FWO herself recognized, for this group of workers, their "primary concern is often their visa status as opposed to their minimum rate of pay" (James 2017, 14 September). The FWO has implemented several initiatives that seek to tackle this particular problem.

First, in an attempt to reduce some of the barriers facing migrant workers and encourage reporting to the regulator, the FWO has developed a Multicultural Access and Equity Plan, which includes development of in-language information tools, and the introduction of a dedicated telephone enquiry line for visa holders. In addition, the FWO has further ramped up collaborations with community groups both on the employer and employee side - in an attempt to educate key ethnic communities about workplace rights and responsibilities (FWO 2017a, 18).

In September 2017 the FWO published an open letter to international students making it clear that they have the same rights as all workers in Australia. More recently, and for the first time, the FWO has entered into, and publicized, a formal protocol with the Department of Home Affairs. The protocol provides that a workers' temporary visa will not be cancelled if they report exploitation, are actively assisting the FWO with an investigation, and commit to comply with future visa conditions.

In our view, there are three alternative activities carried out by the FWO that are better placed to capture contraventions that affect vulnerable workers, without necessarily compromising the employee's visa status or future work prospects. It is important to recognize that while these activities may enhance the FWO's ability to identify contraventions at different scales and track key trends, these detection mechanisms may not necessarily lead to improved redress for workers (Berg and Farbenblum 2017). 
The first relevant initiative is the FWO's Anonymous Report tool (FWO 2018, February). Since introducing this reporting tool - which is now available in up to sixteen languages - the agency has received more than 20,000 tip-offs alleging potential contraventions of workplace laws. These reports emanate from concerned members of the community, including workers themselves, competitor businesses, and the general public. This tool is especially significant in high-risk sectors. For instance, the hospitality industry (a sector renowned for rampant non-compliance) accounts for 17 per cent of all complaints but features in more than 36 per cent of all anonymous tip-offs (FWO 2018, February). While there have been some limited instances where tip-offs have triggered a full and immediate investigation, in most instances the data captured through anonymous reporting is generally pooled with "intelligence" gathered from a range of other sources, including referrals and information obtained from community groups, industrial associations, government ministers, and the media, to map and measure risks to a relevant business, locality, industry, or network (FWO 2018b). This pooled information is then used to determine the focus and direction of other compliance and enforcement activities, including campaigns and inquiries. Indeed, the previous head of the FWO observed, "When we see vulnerable workers coming to us for help, we do look closer, because unfortunately these examples tend not to be isolated incidents or an error, but indications of a broader pattern of non-compliance. Acknowledging that in spite of our best efforts, vulnerable workers do not always come to us for help, the Fair Work Ombudsman digs deeper" (James 2017, 14 September).

While campaigns vary in scope and methodology, the FWO has suggested that targeted activities are best suited to segments of the labour market where employees are least likely to complain but are most exposed to the risk of underpayment. In 2017/18 the FWO undertook 4,572 audits of businesses and recovered around $\$ 6.1$ million in unpaid wages (which represents 21 per cent of all monies recovered by the FWO in the same fiscal year). Almost half of these audited businesses were found to be non-compliant with basic workplace laws (FWO 2018a). In a previous report, the FWO had observed that the continuing poor compliance rate reflects "an improved ability to target businesses suspected of non-compliance, rather than signifying a decrease in overall workplace compliance" (FWO 2017a).

The importance of auditing is underlined by our recent survey of around 600 businesses exploring their perceptions of, and responses to, FWO's enforcement activities. This research revealed that respondents had a greater fear of detection than of sanction (Hardy and Howe 2017). In light of this finding, it is somewhat confounding that 
campaigns are routinely undertaken on an announced basis, as in Ontario (see chapters 5 and 6; in the United States, by contrast, inspections are not announced, see chapter 11), generally adopt a desk-based audit methodology rather than site visits (contrary to Ontario and the United States), and have a strong educational bent, as in Ontario (see chapters 2 and 5). This somewhat outdated approach appears to reflect the "flexible compliance" approach adopted more generally by the FWO in its earlier years (Workplace Express 2010, 2 June).

However, in line with the findings in Ontario, there is growing evidence that non-compliance with labour standards in Australia is not due to a lack of understanding, but "a strategy of labour cost reduction for a growing number of employers" (Vosko, Grundy, and Thomas 2016, 379). Continuing with the FWO's default format for campaigns may be more efficient from a resourcing perspective, and less hostile from an inspector's point of view, but it has exposed the FWO to heavy criticism. More generally, campaigns that emphasize education and voluntary compliance over auditing and deterrence may compromise the overall regulatory value of targeted audits.

The shortcomings of desk-based audits, and the value of site visits, is highlighted by the apparent extent of non-compliance with record-keeping requirements. In 2016/17 the FWO reported that 73 per cent of all enforcement proceedings concerned with wages and conditions also alleged pay slip and record-keeping contraventions. The FWO indicated that because there were insufficient records, it was unable to calculate all or some of the underpayments owed to employees in many of these matters. More worrying still is the fact that almost one third of the litigation initiated in the 2016/17 financial year alleged that the employer had created false or misleading workplace records in order to deliberately mask the non-compliance (FWO 2017a, 23). In 2017 the head of the FWO, Natalie James, noted, "Unless workers have meticulously kept their own records of their hours of work, it becomes very difficult to assess whether underpayments have arisen" (James 2017, 1 May, 2). These problems are potentially exacerbated by the FWO's conservative approach to litigation and investigation. Our research has revealed that the agency overemphasized the need for documentary evidence and undervalued oral testimony from workers. A consequence of this approach is that the worst offenders were often let off the hook (Howe, Hardy, and Cooney 2014; Berg and Farbenblum 2017, 326).

The current situation underlines the critical importance of the reforms to record-keeping provisions and investigative powers that were introduced under the PVWA. While these provisions are yet to be tested, it is quite possible that the reverse onus of proof, along with 
increased uptake of the FWO's Record My Hours app by employees (FWO 2018e), is likely to be a game changer. Addressing record-keeping issues is not only important in relation to campaigns, and not only critical in matters that reach litigation, but they may also be important in bolstering the bargaining position of employees who find themselves seeking recovery through the FWO's dispute resolution process or in the small claims court. Most importantly, it may prompt the FWO to reconsider its own biases in assessing the merits (or otherwise) of workers' claims. Improving record-keeping may have flow-on implications for how the agency assesses which regulatory response is most "appropriate." Generally speaking, mediation is viewed as suitable by the FWO where there is conflicting or limited evidence, which is perceived to make investigation and litigation more difficult. However, it is arguable that the new evidentiary presumptions introduced under the PVWA should effectively shift this criterion in favour of employees in many cases.

The third activity we want to highlight is a relatively new initiative of the FWO and one that differs quite substantially from campaigns: the formal, public enquiry. These in-depth inquiries - twelve of which have now been concluded - are generally prompted by allegations or concerns about systemic employer non-compliance in an industry, region, supply chain, or labour market. They normally entail the regulator undertaking a detailed examination of the drivers of compliance through site visits, interviews, and payroll audits. Specific focus is placed on the role of lead firms. At the conclusion of an enquiry, a report is made publicly available, which sets out the key findings, the regulator's recommendations, and any actions taken, including whether the regulator has initiated (or is likely to initiate) enforcement litigation against one or more persons (FWO 2015).

On the one hand, these inquiries - which require huge resources can be justified by the fact that they have generated enormous media interest and have inflicted serious reputational damage. On the other hand, the recommendations of FWO at the conclusion of these inquiries, while embarrassing, have sometimes proved insufficient to compel the lead firm to readily submit to voluntary initiatives, particularly in the absence of credible threats of liability.

\section{Dispute Resolution and Mediation}

In most instances, and much in line with the MOL's approach, the FWO encourages prospective complainants to engage in self-help by raising the relevant issues with the employer (on the Ontario case, 
see chapter 2). If this direct method fails to achieve the desired outcome or is deemed inappropriate, a team of experienced FWO staff then assess the matter, using a fixed set of criteria to determine the level of resources and assistance to devote to resolving the complaint. According to the FWO's Compliance and Enforcement Policy, in determining which response is most "appropriate," the assessors will consider a host of factors, including any past attempts to resolve the matter; the seriousness of the alleged conduct; the relevant characteristics of the parties; the confidentiality of the process; if and when the employment relationship ended; whether there is sufficient information and evidence to support an argument that a breach has occurred; and the public interest (whether the community expects the FWO to be involved) (FWO 2017b, 10).

Given the flood of requests for assistance that the FWO continues to receive (FWO 2017a) $)^{3}$ and its small inspectorate, dispute resolution has become increasingly critical for the regulator. In the last fiscal year, over 96 per cent of requests for assistance received by the FWO were resolved through education and dispute resolution (FWO 2018a, 9). While a resolution was reached more quickly (an average of 7 days), as compared to requests that were resolved through investigation and enforcement channels (an average of 167 days), the average amounts recovered by employees were far more modest (AU\$768 in the case of dispute resolution, AU\$2248 following an FWO "compliance activity") (13).

While the speed or quantity of resolutions is not a firm indicator of the nature or quality of the outcome, an efficient "resolution" of a complaint is clearly perceived favourably. This is reflected by the fact that one of the FWO's key performance measures is assessed by reference to the "average number of days requests for assistance involving a workplace dispute are finalized." In 2017/18 the target was thirty days and the FWO reported that the average resolution time was fourteen days (FWO 2018a, 9). While the desire for a speedy resolution can be detrimental from a regulatory perspective, it can be especially important in a practical sense - that is, when the worker is seeking rectification of an underpayment from a business that is financially precarious. If the business fails, then most redress mechanisms are rendered relatively futile. In these circumstances, the employee may be forced to rely on the federal government's Fair Entitlements Guarantee scheme (a legislative safety net to cover unpaid employment entitlements) (Fair Entitlements Guarantee Act 2012 (Cth); Anderson 2014). ${ }^{4}$

In line with these concerns, the mediation service is promoted by the FWO as a "fast, confidential and free way to help employers and employees find solutions to disputes about workplace issues" 
(FWO 2018e). However, given that mediations have a time limit of two hours and are conducted by telephone, there is limited capacity for the mediators to make any legal assessment of the employee's relevant rights and entitlements. In any event, that is not the objective of the exercise. Rather, the mediator is said to take "a neutral stance" (FWO 2017a, 12) in order to "allow parties to create their own solutions to disputes, instead of having a decision made by someone else" (FWO 2018g).

As was pointed out in the chapters comprising Part One, negotiated settlements that lead employees to accept less than their legal entitlement effectively turns questions of law enforcement into matters of dispute resolution (see also Vosko, Noack, and Tucker 2016). Similarly, adopting a position of mediator neutrality not only masks inequalities of bargaining power, it potentially compounds them.

While the FWO dispute resolution model may be quick and cost-effective in solving individual complaints, the privatization of the deliberations and outcomes means that these processes may do little to develop and legitimize norms of workplace practice beyond the individual employer (Riley 2009). They not only diminish the diffusion of best practice, they also tend to "limit the exemplary power of the law; that is the extent to which justice is seen to be done" (Colling 2004, 573). Although mediation may provide an avenue for short-term redress for workers, it may ultimately exacerbate the overall enforcement gap; by perpetuating perceptions that there is a low probability of detection and sanction, employers may be further emboldened and workers further silenced (Hardy 2014).

Although these issues are all significant, it is also arguable that if a labour inspectorate wants to engage in strategic enforcement and more proactive and preventative measures, then engaging in dispute resolution processes may be a necessary evil. In very crude terms, by resolving complaints quickly and cheaply, the labour inspectorate is not only able to achieve some redress for workers, it is able to redirect precious resources towards more deterrence based activities. That said, triaging must be approached cautiously and conservatively to ensure that vulnerable workers are not left to advocate for their own interests. The role of traditional and alternative labour market intermediaries is absolutely crucial here (Hardy 2011, 2017b).

\section{Administrative Tools and Coercive Sanctions}

Where a contravention is detected and compliance cannot be achieved or is resisted, two main options are broadly available. If the claim is not deemed "appropriate" for further investigation, the FWO may end its 
involvement at this point. In these circumstances, the employee is then left to take action in the small claims jurisdiction, or through the ordinary courts. Even with the assistance of a union or community legal centre, the current costs, rules, and the lack of legal aid makes this a very difficult and expensive path, and successful recovery of the underpayment (let alone penalties) is far from guaranteed (Arup and Sutherland 2009; FWA, s. 570). ${ }^{5}$

Alternatively, a formal investigation may ensue. This scenario is more likely where non-compliance is "serious," namely, there is evidence to suggest that there is exploitation of vulnerable workers; significant public interest or concern; blatant disregard for the law or a court or Fair Work Commission order; deliberate distortion of a level playing field to gain a commercial advantage; or an opportunity to provide an educative or deterrent effect (FWO 2017b). If the contraventions are substantiated, inspectors may then access a suite of regulatory tools, including letters of caution, infringement notices, compliance notices, enforceable undertakings, and proactive compliance deeds (Hardy and Howe 2013; Owens 2016). This range of sanctions is intended to provide "the FWO with another option to deal with non-compliance (by encouraging co-operative compliance) instead of pursuing court proceedings" (Minister for Employment and Workplace Relations 2008, 400).

These formal enforcement tools are not invoked as a matter of course, but rather are reserved for "cases of serious non-compliance where other options such as dispute resolution or small claims are not appropriate to resolve the matter" (FWO 2017b, 22). As table 9.1 shows, use of the most coercive tools available to the FWO - enforceable undertakings and civil remedy litigation - has dropped considerably in the last financial year. The reasons for the decline in deterrence-based mechanisms have not been explained in the annual report, or otherwise. However, it is also important to point out that these raw data do not readily reveal the relative impact of these mechanisms on employees in these workplaces, or on employers in the relevant geographical locality or industry. ${ }^{6}$ This is a critical gap, and the FWO has recognized that

Table 9.1. FWO's Use of Enforcement Tools, 2016-2018

\begin{tabular}{lcc}
\hline Enforcement tool & $2016-17$ & $2017-18$ \\
\hline Infringement notices issued & 665 & 615 \\
Compliance notices issued & 192 & 220 \\
Enforceable undertakings executed & 40 & 7 \\
Litigation proceedings commenced & 55 & 35 \\
Total & 952 & 877 \\
\hline
\end{tabular}


more research is needed here. Not only would such research be useful in showing that the agency has met the fourth relevant key performance indicators - that the FWO has had "a positive impact on sectors/ regions or issues of importance to the community" (FWO 2018a, 9) but it may also guard against the risk that the inspectorate privileges particular regulatory responses on the basis that they are more easily measurable, but ultimately less effective.

Arguably the most visible aspect of the agency's enforcement activities is civil remedy litigation. However, our research of business knowledge of the FWO's enforcement activities reveals that while firms may be broadly aware of the FWO's litigation, there is little recollection of the details. Moreover, our research suggests that the general deterrence effects of lesser-known sanctions (such as enforceable undertakings) may be restricted by general lack of recognition or understanding about the circumstances in which these tools may be used and the relevant consequences.

While the general deterrence of enforceable undertakings and proactive compliance deeds may be less than theory predicts, these instruments continue to deliver other critical regulatory benefits. Similar in some ways to the settlement agreements used by Wage and Hours Division (WHD) at the federal level in the United States, enforceable undertakings and proactive compliance deeds represent a "top-focused enforcement strategy": namely, one that strategically targets lead firms, such as franchisors, in order to build sustained compliance among the subordinate units.

By way of background, proactive compliance deeds are voluntary agreements that are generally struck between a lead firm and the FWO. Unlike enforceable undertakings, proactive compliance deeds are not made under the FWA and are not directly enforceable in court. While there are some differences between enforceable undertakings and proactive compliance deeds in application and enforceability, the instruments are similar to the extent that both generally require firms to make far-reaching commitments to enhance compliance with workplace laws. For example, under the terms of these instruments, firms frequently commit to engaging an independent and qualified third-party professional to undertake periodic auditing of a sample of employment records and report these findings to the FWO. It is also relatively common for firms to agree to rectify any outstanding underpayments within their firm (or in some cases, within their supply chain or franchise network); implement workplace training; set up an employee complaints hotline; and donate an agreed sum to a community group or legal centre. 
In general the FWO has promoted enforceable undertakings and proactive compliance deeds as a way for franchisors, and other reputation sensitive firms, to protect their brand. While enforceable undertakings and proactive compliance deeds have allowed the FWO to preserve resources by shifting some of the enforcement burden to powerful lead businesses, there is growing unease about these "softer" mechanisms. For a start, it is increasingly uncertain to what extent (if at all) lead firms would be willing to adopt voluntary compliance mechanisms in the absence of consumer pressure, regulatory scrutiny, and/or the credible threat of liability. The former head of the FWO has observed, "Franchisors can be reluctant to proactively engage with the FWO before issues are uncovered, either by the FWO or through the media. Reputational leverage works as a 'push' factor for franchisors to act, but has had limited effect as a general deterrence measure to encourage other franchisors to take reasonable steps to detect non-compliance and support franchisees to be compliant" (FWO 2017d, 14). Indeed, even where lead firms have actively cooperated with the FWO and made formal commitments to improve compliance under the auspices of an enforceable undertaking or proactive compliance deed, it is not clear that these commitments have actually translated to substantive, rather than cosmetic, improvements in compliance (Ferguson and Christodoulou 2017).

In the last few years the regulator has acknowledged that leveraging reputational concerns is not sufficient, especially where this is not supported through a credible sanctioning regime. But ensuring that the relevant collaboration - whether through enforceable undertakings, proactive compliance deeds, or otherwise - is rigorous, independent, and accountable has also proved difficult. Indeed, the challenges summarized underline the importance of "hard" enforcement mechanisms (Vosko, Grundy, and Thomas 2016, 379).

\section{Holding Key Persons, Advisors, and Entities to Account}

\section{Accessorial Liability}

Under the statutory regime in Australia, the principal mechanism by which the FWO has sought to hold parties to account has been via a threat of accessorial liability under the FWA. Under these provisions, persons found to be "involved in" a contravention of the FWA may be liable under a civil remedy provision, even where they are not the actual employer of the worker whose rights have been breached. Broadly speaking, a person will be taken to be "involved in" a contravention if 
the person has aided, abetted, or been in any way, by act or omission, "knowingly concerned" in the contravention (FWA, s. 550(2)(c)).

The FWO has been particularly active and innovative in using the accessorial liability provisions to diversify the target of its litigation beyond the direct employer. In the 2016/17 financial year, an accessory was named in over 90 per cent of all proceedings (FWO 2017a, 22). Holding key individuals and advisors, such as company directors, HR managers, lawyers, and accountants, liable for underpayment contraventions has practical advantages and regulatory benefits.

At a practical level, ascribing liability to an accessory often allows for full or part rectification of an underpayment claim, where this would not otherwise be possible as the result of liquidation or deregistration of the employer entity (Fair Work Ombudsman v Step Ahead Securities [2016] FCCA 1482). Further, in order to maximize the chances for full recovery of the underpayment, the FWO has been increasingly creative in relation to court-based remedies. In the recent past, the FWO has sought orders requiring accessories to pay compensation (in addition to penalties) (Fair Work Ombudsman v WY Pty Ltd, Chong Yew Chua and Ning Yuan Fu [2016] FCCA 343; Anderson and Howe 2012), freezing orders in relation to accessories' assets (Fair Work Ombudsman v Trek North Tours [No 2] [2015] FCCA 1801), and restraints in relation to potential future contraventions (FWO $v$ James Nelson Pty Ltd \& Anor [2016] FCCA 531).

From a regulatory perspective, threatening or attributing liability to "gatekeepers" (i.e., individuals who can monitor and control corporate conduct) provides a direct incentive for these individuals to perform their responsibilities effectively and to deter corporate wrongs (Kraakman 1986). In a landmark case, the FWO used the accessorial liability provisions to obtain penalties against an accounting and payroll firm for "knowingly helping one of its clients exploit a vulnerable worker." The trial judge acknowledged that while the relevant accessory - Ezy Accounting 123 Pty Ltd - was not directly responsible for the underpayment, "Ezy was involved in a relationship with [the employer entity] where it provided payroll services. As such it must put compliance with the law ahead of business interests. Ezy had a responsibility to ensure there was compliance with, inter alia, the FWA" (Fair Work Ombudsman v Blue Impression Pty Ltd [2017] FCCA 2797 at [105]; decision upheld on appeal: EZY Accounting 123 v FWO [2018] FCA 134).

The FWO has also been willing to test the boundaries of the law in fissured work arrangements, and the agency has increasingly sought to bring proceedings against non-employer firms in supply chains or other business networks (Hardy and Howe 2015; Hardy 2016). However, this has had more limited success, particularly in franchises. 
The limitations of the accessorial liability provisions in this context became glaringly apparent in the 7-Eleven case. While the FWO found, as part of an in-depth enquiry, that the Australian franchisor, 7-Eleven Stores Ltd., had frequently failed to prevent or detect franchisee contraventions of workplace laws, the regulator ultimately concluded that there was insufficient probative evidence to pursue the franchisor under the accessorial liability provisions of the FWA (Hardy 2017a). In the absence of litigation, the franchisor ultimately entered into a "compliance partnership" with the FWO.

One of the problems identified in the 7-Eleven case is that, unlike employer contraventions of minimum employment standards, which are ordinarily ascribed on a strict liability basis, to impose liability on accessories the FWO must prove that the person had the requisite level of knowledge about the contraventions (Fair Work Ombudsman v Devine Marine [2015] FCA 370; Potter v Fair Work Ombudsman [2014] FCA 187; Ranieri 2018). The knowledge threshold has been interpreted narrowly by the courts, and this has made it more difficult, though not impossible, to pin liability on the alleged accessory in a supply chain or franchise network (see, e.g., Fair Work Ombudsman $v$ Yogurberry World Square Pty Ltd [2016] FCA 1290).

\section{Protecting Vulnerable Workers: A Summary of Key Statutory Reforms}

The PVWA is designed explicitly to address the fact that some franchisors may "operate on a business model based on underpaying workers" and "have either been blind to the problem or not taken sufficient action to deal with it once it was brought to their attention" (Minister for Employment 2016-17, 6). In particular, the PVWA makes franchisors and parent companies responsible for underpayments by their franchisees or subsidiaries respectively where they knew or ought reasonably to have known of the contraventions and failed to take reasonable steps to prevent them (FWA, s. 558B). In addition, the PVWA has increased the maximum penalties available for "serious contraventions" of prescribed provisions of the Act by a factor of ten (FWA, s. 557A). This increase may allow the regulator to seek severe fines against employers who knowingly and systematically contravene prescribed employment standards. ${ }^{7}$

\section{Difficulties of Deterrence}

However, some of our more recent research of business awareness of, and responses to, deterrence raises doubt about the extent to which penalties will have the expected or predicted deterrence effects. In summary, 
our findings mirrored the findings of earlier research into deterrence in occupational health and safety regulation, which suggested that key individuals within firms generally displayed "a very significant degree of inattentiveness to information on penalties for non-compliance" (Purse and Dorrian 2011,32). This finding seems to run counter to the idea that businesses are rational and calculative - if they cannot recall the target or amount of the penalty (i.e., the potential costs), then they cannot weigh this up against the costs (and benefits) associated with compliance.

Nevertheless, our findings suggest that enforcement litigation may still be having positive compliance effects. For example, our survey revealed that even though the constrained resources of the FWO mean that it can conduct audits of a small subsection of all employing businesses, and pursues litigation only in limited instances, almost half of businesses believed that it would be likely or highly likely that the FWO would detect business underpayment of workers, and almost 70 per cent felt that it was at least likely that underpayment would be penalized. These results suggest that the FWO is generally seen as much more powerful by the regulated community than may actually be the case (Hardy and Howe 2017). This is a critical finding, given that previous research has found that "the perception of deterrence itself can make a significant difference to any deterrent effect, over and above that associated with the likelihood of detection of ... offences and the imposition of sanctions" (Purse and Dorrian 2011, 24).

Finally, while our results did not confirm that deterrence-based mechanisms function in the way predicted by theory, our survey findings supported the idea that many firms - who were already motivated to comply with the law - took knowledge of the FWO's enforcement as either reassurance that competitors who were not compliant would be detected and punished, or took the knowledge as a reminder to review their internal systems to ensure that they were compliant.

\section{Conclusion}

The move away from conciliation and arbitration as the basis for employment standards regulation not only marked a new era in standard-setting, but also prompted a watershed in regulatory enforcement of minimum employment standards. Unfortunately, despite the spirited attempts of the federal labour inspectorate over the past decade or so, there remains a vast enforcement gap. As in Ontario, this gap appears to be of catastrophic proportions in certain segments of the labour market (e.g., in the Australian context, amongst international student workers and within franchise networks). 
The FWO has continued to modify its approach in response to political demands and community expectations, as well as a deeper appreciation of the breadth, depth, and underlying drivers of these problems. The FWO has developed and rolled out new tools to enhance detection and support migrant workers to report exploitation. It has sought to leverage reputational concerns of big business in a bid to coerce them into using their power, authority, and resources to monitor subordinate businesses in their networks and prod them into compliance. While these initiatives are valuable, there are limits to their utility. Recent amendments to the FWA - extending liability to franchisors and holding companies, increasing sanctions for serious contraventions, and reversing the onus of proof in the absence of employment records - are critical for strengthening the regulatory power of the FWO.

This chapter has identified close parallels and striking differences between the FWO and its Ontario counterpart. For example, labour inspectorates in both jurisdictions have embraced self-help strategies and dispute resolution processes. While there may be a range of practical and political reasons for adopting this approach - not least of which are quantitative key performance indicators - reducing reliance on dispute resolution may create a separate set of challenges. It appears, in particular, that both regulators are struggling to strike the right balance between ensuring access to justice and providing adequate avenues for employee redress, while still preserving sufficient resources to undertake proactive and strategic activities to prevent contraventions in the first place. 


\section{University Library}

\section{- M M I N E R VA \\ A gateway to Melbourne's research publications}

Minerva Access is the Institutional Repository of The University of Melbourne

Author/s:

Hardy, T;Howe, J

Title:

Out of the Shadows and into the Spotlight: The Sweeping Evolution of Employment Standards Enforcement in Australia

Date:

2020

Citation:

Hardy, T. \& Howe, J. (2020). Out of the Shadows and into the Spotlight: The Sweeping Evolution of Employment Standards Enforcement in Australia. Vosko, L (Ed.). Closing the Employment Standards Enforcement Gap: Improving Protections for People in Precarious Jobs, (First Edition), pp.221-241. University of Toronto Press.

Persistent Link:

http://hdl.handle.net/11343/265731

License:

Unknown 